\title{
Perspectivas de la investigación en fitopatología
}

\author{
ERNESTO MORENO-MARTINEZ \\ Unidad de Investigación en Granos y Semillas, \\ UNAM-INIFAP Pabellón de Arteaga, Ags.
}

\begin{abstract}
Resumen. Aproximadamente treinta plantas cultivadas proveen al mundo con la mayor parte de las calorías y proteínas para la alimentación humana y animal constituyendo el $90 \%$ de la dieta humana. Dentro de la tendencia actual de preservar los recursos naturales, el concepto de agricultura sostenible puede revertir la actual crisis alimenticia. Este concepto plantea un mejor uso y protección de los recursos naturales y un manejo adecuado de los materiales utilizados en la producción de alimentos (por ej., fertilizantes, pesticidas, etc.) para lograr producir alimentos en regiones actualmente deficientes con un mínimo de compromiso con el ambiente.

Las enfermedades de las plantas siempre han afectado la producción de alimentos. En los últimos quince años, un considerable número de enfermedades afectó la producción de cultivos de gran importancia en México y en otros países latinoamericanos. La investigación realizada en México ha logrado combatir muchas de las enfermedades que limitaban la producción agrícola. Un caso significativo es el del grupo de investigadores mexicanos encabezado por Dr. Norman E. Bourlag, Premio Nobel de la Paz en 1970, quienes estudiaron la resistencia de ciertos cultivos de trigo al patógeno Puccinia graminis fsp tritici, la roya del tallo, que afectaba la producción de trigo en varios países del mundo.

Durante este siglo se han logrado importantes avances en el terreno del cultivo de plantas, el uso más eficiente del suelo y el agua, y el desarrollo de maquinarias agrícolas. Sin embargo, hoy en día, los esfuerzos deben de estar dirigidos hacia el uso prudente de sustancias químicas en beneficio de la integridad ambiental global. Los logros de la biotecnología moderna en particular el cultivo de tejidos y la ingeniería genética, hacen ver el futuro de la producción de alimentos con gran optimismo. Dos de los retos más importantes para nuestro país en la biotecnología agrícola son la formación de recursos humanos altamente calificados en las disciplinas que conforman a esta área del conocimiento científico y tecnológico y la formación de grupos de investigación ligados a los problemas que aquejan a la producción agropecuaria.
\end{abstract}

Abstract. Approximately only 30 cultivated plants provide the world supply of calories and proteins constituting more than $90 \%$ of the human diet. One of the strongest trends toward preserving global natural resources, which has the potential to reverse the current world food crisis involves the concept of sustainable agriculture. This concept allows for better use and protection of natural resources and more efficient management of materials for food production (e.g., fertilizers, pesticides, etc) toward the production of food in regions which are currently deficient with a minimum compromise of the environment.

Plant diseases have always created a problem for food production worldwide. In the past fifteen years, a variety of plant diseases have threatened crops of great economic importance in México and in other Latin American countries. Research performed in Mexico has been responsible for greaty alleviating some of the compromise to agricultural production caused by these plant diseases. In the case of wheat, the stem rust was finally brought under control by the brilliant research achievements of Dr. Norman E. Borlaug and his team of Mexican scientists, who in 1970, received the Nobel Prize for World Peace.

The agricultural research of this century has yielded enormous advances in plant breeding, in the use of soil and water, in the development of agricultural machinery for growing as well as harvesting crops. Now, however, the focus must be toward a more prudent use of chemicals in the name of global environmental integrity. The achievements of modern biotechnology through the use of special techniques such as tissue culture and genetic engineering contribute to an optimistic vision of world food production for the future of mankind. Two of the most important challenges for our country in the field of agricultural biotechnology are the upbringing of highly qualified human resources and the formation of research groups in touch with the problems that affect agricultural production.

\section{INTRODUCCIÓN}

Directa o indirectamente, las plantas proveen al hombre de alimentos así como de otros importantes satisfactores, como el vestido, la madera para construcción, algunas medicinas y también algunos de sus placeres, entre ellos el café y el tabaco. En relación con los alimentos, las plantas constituyen poco más del $90 \%$ de la dieta humana, con aproxima- damente treinta plantas cultivadas, que proporcionan al mundo la mayor parte de las calorías y proteínas para la alimentación humana y animal. Los productos de origen animal aportan el 7\% de la dieta del hombre y la producción animal está basada prácticamente en las plantas cultivadas.

De las plantas cultivadas de mayor importancia económica, los cereales constituyen el $52 \%$ de la alimentación 
mundial. Las raíces son el segundo grupo en importancia, seguido de las leguminosas, de los cultivos horto-frutícolas, de la caña de azúcar y de la remolacha azucarera.

Existen dos aspectos importantes sobre el problema de alimentar a la creciente población mundial, uno de ellos de tipo científico y tecnológico, y el otro de tipo económico y político. El primero está comprometido con la producción de suficientes productos agropecuarios para la demanda de alimentos de los pueblos del mundo.

El aspecto económico y político es sin lugar a dudas de mayor complejidad, porque implica la distribución equitativa de los alimentos. Esa distribución o disponibilidad equitativa de los alimentos, en el tiempo y lugar requeridos, está definida por el poder adquisitivo del hombre, lo que a su vez está determinado por la falta de empleos, aun en países desarrollados. En los países en vías de desarrollo, la no disponibilidad de los alimentos está definida por los niveles de pobreza de los habitantes; se trata de países carentes de tecnología, de recursos económicos y de programas o planes de desarrollo que les permitan vislumbrar un mejor futuro en sus más apremiantes necesidades, como lo es la disponibilidad regional de alimentos. La producción de alimentos a nivel regional, para el caso de los países pobres, es en cierta forma una garantía para asegurar la disponibilidad de alimentos básicos más baratos, si se les compara con los alimentos importados ya sea de otras zonas del país o del extranjero.

Por otro lado, la pobreza en sus diferentes niveles, se verá siempre más agravada por el crecimiento no controlado de la población, lo cual y desafortunadamente es más evidente en los países tecnológicamente no desarrollados. El control de la natalidad se ha manejado en forma muy persistente, y en ocasiones en forma agresiva, con el fin de aminorar el problema del hambre; indudablemente que el control del rrecimiento poblacional ayuda, pero de ninguna manera es la total solución del problema. Además de un control pactado del crecimiento de la población, lo que se requiere urgentemente son fuentes de trabajo. Esto implica una planificación de las economías y desarrollos regionales, aunada a una mejor educación.

Actualmente existen tendencias que se manifiestan firmemente para la producción de alimentos y la preservación del ambiente. Dentro de ellas podría encontrarse una solución al problema alimentario, sobre todo a nivel regional, a través de la producción de alimentos bajo el concepto de agricultura sostenible. Es decir, aquella que permita un mejor uso y protección de los recursos naturales, un uso consciente de los insumos agrícolas y el empleo organizado de la fuerza y de la creatividad del trabajo del campesino. Esto garantizaría la producción de alimentos en las áreas actualmente deficientes y con un deterioro mínimo del ambiente, lo cual es factible. Sólo se requiere la decisión política y el apoyo económico y técnico para iniciar el camino hacia esa meta. Bajo estas condiciones de producción de alimentos, indudablemente que se tendría una agricultura protectora del ambiente y para ello se requiere de nuevos enfoques en la práctica de esta importante actividad, lo cual demanda investigación innovadora; por ejemplo, para el combate de las enfermedades de las plantas. Esto último es todavía de mayor importancia para la llamada agricultura orgánica, en donde se requiere de una absoluta eliminación de los plaguicidas y demás sustancias químicas empleadas en la agricultura intensiva. La agricultura orgánica, actividad agrícola de moda, tiene sus muy particulares peculiaridades que la hacen diferente, en lo social y en lo económico, de los tipos de agricultura convencionales; por lo tanto requiere ser considerada de manera especial.

Desde el inicio de la agricultura y aun en la primera parte del siglo pasado, a través de la selección de los mejores fenotipos de plantas y animales, los avances en la producción de alimentos de origen agropecuario estuvieron prácticamente en manos de los propios agricultores, quienes heredaron de sus antepasados los cultivos agrícolas y los animales domesticados por el hombre a lo largo de miles de años con gran paciencia y sabiduría. Recientemente no se ha hecho nada semejante.

Indudablemente, el mejoramiento genético de los cultivos ha jugado un papel muy importante en el éxito de la agricultura contemporánea. Este mejoramiento se inició con los estudios básicos realizados desde el siglo XIX hasta la actualidad. Tal es el caso del trabajo de Charles Darwin publicado en 1859 sobre la variación de las especies; las investigaciones de Gregor Mendel, en 1865, sobre las leyes de la genética y las de Thomas Hunt Morgan, en las primeras décadas de este siglo, que sentaron los lineamientos del arreglo lineal de los genes en los cromosomas. Posteriormente, en 1953 con el descubrimiento de la estructura del ADN por James Watson y Francis Crick se inició la etapa moderna de la genética: la genética molecular. Se tiene gran confianza en que la biotecnología moderna, a través de las herramientas de la biología molecular, genere logros en la producción de alimentos y en el mantenimiento de la calidad del medio ambiente.

Los estudios de los microorganismos y las enfermedades de las plantas, que fueron realizados por grandes científicos a partir del siglo XVIII, permitieron el avance de las diferentes disciplinas relacionadas con el cultivo de las plantas, como la fitopatología. Estas disciplinas, así como la domesticación de las plantas de las que ahora derivamos nuestra alimentación, sentaron las bases para la agricultura productiva de este siglo. En 1775, Tillet observó que el polvo negro (esporas del hongo) estaba involucrado en el desarrollo de la enfermedad del trigo conocida como carbón. Sin embargo, no fue sino hasta 1853 cuando Anton DeBary, investigando los carbones y las royas del trigo, estableció en forma conclusiva que los hongos eran la causa y no el resultado de las enfermedades (Large, 1940). Posteriormente se definió el papel de las bacterias, de los nemátodos, de los virus, y recientemente el de los micoplasmas y viroides, en el desarrollo de las enfermedades de las plantas.

Muchos de los trabajos básicos que dieron lugar a la fitopatología, aparentemente sencillos a la luz de la inves- 
tigación que ahora se realiza, fueron desarrollados por investigadores como Tillet, los hermanos Tulasne, DeBary, Brefeld, Burrill, Needham, Ivanowski y Beijerinck. Estos científicos se basaron en sus observaciones y conocimientos, en su creatividad, en su tenacidad y en su paciencia, sin el apoyo de equipos como los que ahora tenemos. Lo anterior hace recordar la siguiente anécdota, ocurrida en la Universidad de Minesota en uno de los seminarios del Departamento de Fitopatología. Un candidato al doctorado disertaba sobre la roya del trigo, a propósito de las interacciones bioquímicas y fisiológicas entre la planta de trigo y el hongo Puccinia graminis tritici. Al final del seminario el Dr. Elvin C. Stakman, Profesor Emérito del Departamento y uno de los más distinguidos fitopatólogos que han existido, pidió la palabra y dirigiéndose a todos los asistentes al seminario dijo: «Me siento muy orgulloso de ustedes porque conocen y discuten aspectos básicos tan importantes de las enfermedades, como los hoy aquí tratados, pero espero que nunca olviden a qué profundidad se siembra el trigo». Entre las contribuciones importantes del Dr. Stakman están sus estudios sobre la identificación de razas fisiológicas del mismo hongo Puccinia graminis tritici, conocimientos que fueron básicos para poder generar variedades de trigo resistentes a esa enfermedad, que limitaba la obtención de buenas cosechas en todo el mundo.

\section{LA FITOPATOLOGÍA Y LA PRODUCCIÓN DE ALIMENTOS}

Las enfermedades de las plantas siempre han sido limitantes en la producción de alimentos. Un ejemplo clásico de ello fué la hambruna en Irlanda en el último tercio del siglo pasado, ocasionada por la destrucción de los plantíos de papa por el hongo Phytophthora infestans, hambruna que ocasionó la muerte de cerca de un millón de irlandeses y la migración de otro tanto a los Estados Unidos. Como ese ejemplo, se pueden citar otros grandes desastres ocasionados por las enfermedades de las plantas cultivadas, como la roya del café, los carbones de los cereales, el mildiú de la vid, entre otros (Large, 1940). La producción de alimentos y su disponibilidad final por parte de los consumidores, además de ser un problema de tipo económico y político, es también un problema de tipo tecnológico, particularmente en las regiones del mundo con más problemas sociales y económicos.

Es en estas regiones en donde las enfermedades de las plantas, han sido y seguirán siendo una amenaza para la producción de alimentos. La solución de los problemas de producción regional de alimentos no solamente se justifica como una actividad productiva, sino que es de alta conveniencia para toda la sociedad en el mantenimiento de la paz social.

Las enfermedades de las plantas son estudiadas por la fitopatología, disciplina científica de la botánica económica. Se entiende por enfermedad de una planta a cualquier desviación de su estado normal que altere o interrumpa sus funciones vitales, como una respuesta a la acción individual o combinada de factores físicos, bióticos o hereditarios, cuyos efectos se reflejen en el rendimiento y en la calidad de las cosechas.

Es materia de la fitopatología estudiar a los agentes causales de enfermedades, y a la interacción de éstos con las demás condiciones ambientales que favorecen el desarrollo de las enfermedades. Igualmente estudia la naturaleza de los mecanismos físicos o biológicos que ocasionan las enfermedades, entre ellos las interacciones físicas, bioquímicas y fisiológicas que establecen los patógenos y las plantas. El objetivo de todo lo anterior es el de llegar a un claro entendimiento de la naturaleza de las enfermedades, para así desarrollar y emplear métodos y técnicas adecuados en la lucha contra ellas. Dada la naturaleza de las plantas y de los agentes causales de las enfermedades, la fitopatología, tanto en su aspecto científico como en su ejercicio práctico, depende del conocimiento básico de diversas disciplinas científicas, entre ellas: la micología, la bacteriología, la nematología, la virología, la meteorología, las ciencias del suelo, la anatomía, fisiología y ecología vegetal; la bioquímica; la genética; la física y la biología celular y molecular. Depende también de la economía agrícola y la sociología rural. En este contexto, la formación de los fitopatólogos requiere de una preparación sólida en esas y otras ramas del conocimiento, que les permitan captar la esencia de su entorno científico y económico, así como la capacidad de poder transmitir sus conocimientos y hallazgos a los diferentes sectores interesados en el ejercicio de sus actividades científicas y tecnológicas.

Por lo tanto, la finalidad de la fitopatología es la de ayudar al hombre a obtener mayores cantidades de alimentos de alta calidad nutricional y sanitaria. Por las contribuciones de esta disciplina, actualmente se cuenta con diversos métodos para aminorar los efectos nocivos de las enfermedades. En cualquier texto de fitopatología, se pueden encontrar los métodos recomendados para el control de las enfermedades, que incluyen medidas legales, como las cuarentenas y las inspecciones, las prácticas de cultivo, el uso de la resistencia genética de los cultivos, así como recomendaciones en el uso común de las sustancias químicas.

La investigación agrícola, que en este siglo ha tenido enormes avances en el mejoramiento genético de los cultivos, en el uso y manejo del suelo y agua, en el desarrollo de maquinaria y de técnicas sofisticadas para trabajar la tierra, y manejar los cultivos y sus cosechas, ahora debe enfocar sus esfuerzos para acelerar el desarrollo de nuevos cultivares de alta productividad y calidad, y disminuir el uso de agroquímicos, sobre todo los de alto riesgo para la contaminación de los ecosistemas.

El uso de los plaguicidas, medida que se ha llegado a considerar como un mal necesario en la producción de alimentos, últimamente ha sido fuertemente cuestionado por el papel altamente nocivo de algunos de ellos contra los ecosistemas terrestres y acuáticos. En el famoso libro «Silent Spring», Rachel Carson (1962) provocó una reacción en cadena que ha llegado a nuestros días, atrayendo la atención y la preocupación de los gobiernos y de los pueblos 
por el uso indiscriminado, excesivo y descuidado de los plaguicidas. Se ha señalado que el uso de los plaguicidas define la diferencia entre la ganancia y la pérdida en las actividades agrícolas, por lo que los plaguicidas cuentan con un fuerte apoyo de tipo económico. Con algunos plaguicidas la relación costo/beneficio puede diferir, dependiendo de cómo se estimen los daños al medio ambiente y a la salud del hombre, aunque desde el punto de vista meramente económico generalmente se ha asumido que el beneficio es mayor que los «costos». Sin embargo, últimamente la relación costo/beneficio tiende a lo opuesto, cuando se toman con mayor seriedad y precisión los daños a los ecosistemas, y se consideran además los costos sociales. En este sentido, hay países como Suecia, que han tomado medidas muy restrictivas en el uso de los plaguicidas, eliminando en forma total algunos de los que se usan ampliamente en el resto del mundo (Pettersson, 1993). Una línea de investigación interesante, en relación con este tema, es la relativa a determinar estrategias para minimizar el riesgo potencial de la resistencia de los patógenos a los fungicidas, lo cual sería de gran ayuda para controlar en forma más efectiva a los hongos en el largo plazo. Además se evitaría el uso excesivo de los fungicidas en el combate de las enfermedades (Gilpatrick, 1983; Staub y Sozzi, 1984; Dekker,1986).

Otra línea importante de investigación, tendiente a la protección de los cultivos sin el uso de los fungicidas convencionales, es el desarrollo de compuestos que pueden suprimir la expresión de las enfermedades. Ejemplos de esto son el probenazol que controla al hongo Pyricularia oryze en arroz, y los derivados del ácido isonicotínico que protegen a la planta del tabaco de ciertos hongos, bacterias y virus (Ahl Goy et al., 1990)

Como es fácil de comprender, el uso de plaguicidas, particularmente fungicidas, insecticidas y herbicidas, tiene detractores y defensores. Para un gran sector, renuente a abandonar el empleo de estas sustancias químicas, resulta difícil aceptar otro tipo de medidas, como serían el mejoramiento en los métodos de aplicación de plaguicidas, restricciones en su aplicación, y el desarrollo de plaguicidas de corta persistencia, que no sean nocivos a los ecosistemas y que sean específicos para los patógenos, insectos y malezas que se tratan de controlar. Para el desarrollo de esta estrategia se requiere de una investigación orientada a la generación de tecnologías limpias y por lo tanto protectoras del ambiente. Además, para reducir el uso indiscriminado de plaguicidas, se hace absolutamente necesario crear una política ambiental que establezca una conciencia colectiva racional acerca del problema, con las consiguientes normas regulatorias en el uso de los plaguicidas, ya que éstos se seguirán usando hasta no encontrar la manera de sustituirlos. Urge encontrar soluciones al problema general de la contaminación ambiental, en el campo y las ciudades, ya que de no tener soluciones a este grave problema se está comprometiendo la sobrevivencia de los organismos que habitamos este planeta.

En los últimos quince años, en México y en otros países latinoamericanos un buen número de enfermedades ha amenazado y afectado la producción de cultivos de gran importancia para su economía. Entre esas enfermedades destacan una nueva variedad del patógeno de la Sigatoka del plátano, la roya del cafeto, la pudrición de la mazorca del cacao causada por Monilia, lo mildiús de las gramíneas, el carbón de la caña de azúcar y el amarillamiento letal de la palma de coco.

Las investigaciones realizadas en México por el Instituto Nacional de Investigaciones Agrícolas (ahora Instituto Nacional de Investigaciones Forestales y Agropecuarias) han permitido combatir muchas de las enfermedades que limitaban la producción agrícola. En el caso del cultivo del trigo, y en particular en la resistencia de éste a una enfermedad que era limitante para la producción de trigo en nuestro país y otras regiones del mundo, la roya del tallo, Puccinia graminis fsp.tritici, los avances de la investigación fueron tan significativos a nivel mundial, que en 1970 le fue otorgado el Premio Nobel de la Paz al Dr. Norman E. Borlang, líder del grupo mexicano de investigadores que alcanzaron esos logros.

Además de los antes mencionados, en nuestro país hay muchos otros problemas fitopatológicos que afectan a los cultivos agrícolas, tales como los originados en maíz por Fusarium spp. y Ustilago maydis (DC) Cda., que están afectando seriamente la producción de este grano en los estados de Jalisco, Guanajuato y Tamaulipas. Otro problema serio es el hongo Fusarium oxysporum f lycopersici que afecta al jitomate.

En los últimos años, de 1990 a la fecha, el hongo Aspergillus flavus se ha constituido en un serio problema para los productores de maíz en el estado de Tamaulipas, lo que a su vez representa un serio problema de salud pública y animal (Moreno, 1991). Este hongo, invade a las mazorcas cuando el grano se está formando y encuentra las condiciones adecuadas de humedad y de temperatura para producir y secretar en los granos unos metabolitos secundarios de alto poder cancerígeno, conocidos como las aflatoxinas. Este es un problema que también se presenta en los Estados Unidos de Norteamérica, en donde la investigación se ha enfocado en dos direcciones: la destoxificación de los productos contaminados y el mejoramiento genético de la planta de maíz para hacerla resistente a la invasión del hongo, o para evitar la síntesis de las aflatoxinas cuando éste se encuentra en el grano de maíz. Poco se ha avanzado en este último enfoque a través del fitomejoramiento tradicional, por lo que se abrigan esperanzas de que por medio de la biotecnología moderna se logre lo que hasta ahora no ha sido posible: la formación de genotipos de maíz resistentes a la producción de aflatoxinas (Moreno, 1985; Payne, 1992).

Otro problema serio lo constituye una enfermedad en el trigo, el llamado carbón parcial de los cereales, incitada por el hongo Tilletia indica Mitra. Los hongos patógenos de cereales, comúnmente conocidos como carbones, se encuentran entre los primeros microorganismos estudiados por micólogos del siglo XVIII, entre ellos Tillet, micólogo francés, quien en 1755 publicó un excelente artículo sobre 
el carbón del trigo (Tillet, 1755). Tillet demostró que la enfermedad era contagiosa, y que se producía al contaminarse las semillas de trigo con el polvo negro proveniente de semillas enfermas. Sin embargo, él no reconoció al polvo negro como las esporas del hongo, solamente pensó que ese polvo contenía «algo» que era la causa de la enfermedad. Más tarde Prevost (1807), micólogo suizo, publicó un trabajo sobre la causa del carbón del trigo y su prevención. En él confirmaba el trabajo de Tillet, y además demostraba que las esporas eran las entidades infectivas que causaban la enfermedad. En esa ocasión su trabajo no tuvo el reconocimiento e impacto merecido, debido a que otros estudiosos del área estaban convencidos de la teoría de la generación espontánea. Además, un comité de la Academia de Ciencias de Francia rechazó sus conclusiones y tuvieron que pasar cuarenta años para que los hermanos Tulasne confirmasen sus hallazgos (Tulasne y Tulasne, 1847). Estas enfermedades y estos trabajos sentaron las bases para el combate de las enfermedades mediante el tratamiento químico de las semillas. Uno de los hallazgos importantes en el tratamiento químico de las semillas fue el descubrimiento de los fungicidas sistémicos, como el carboxin, producido en la década de los sesenta. Esto hizo posible, mediante el tratamiento de las semillas, el combate de hongos que se alojan en su interior y avanzan internamente por los tejidos de las plantas hasta llegar nuevamente a las semillas.

Como se señaló, en México seguimos teniendo serios problemas con un miembro de estos hongos, el carbón parcial del trigo, Tilletia indica Mitra, el cual infecta al trigo y al triticale durante la floración, causando daños parciales a las semillas. En México se le detectó a principios de la década de los setenta (Duran, 1972). En el caso del trigo, esta enfermedad ha causado en las regiones trigueras del país un serio problema. Si bien no afecta en forma drástica el rendimiento de la cosecha sí afecta en forma seria la calidad del grano, haciéndolo indeseable para la elaboración de harina por el color negro de las esporas y por su olor parecido al del pescado en descomposición, que se debe a la presencia de trimetilamina (Mitra, 1937). Además, esta enfermedad del trigo ha complicado las transacciones comerciales de grano y de semilla de trigo para la siembra, tanto a nivel nacional como internacional. Su combate es difícil y el tratamiento químico de la semilla no es una medida que se considere del todo efectiva, ya que si bien puede eliminar las esporas de la superficie de la semilla, no lo hace con las que están en el suelo, fuera del alcance del fungicida, y que infectarán a las plantas en el momento de la floración. La resistencia genética de los cultivares de trigo es la mejor alternativa, aunque el proceso es largo y aun no se han reportado líneas resistentes. Sin embargo, sí se han observado diferencias entre genotipos en cuanto a la resistencia y susceptibilidad a este hongo (Singh y Dhaliwal,1989; Gill et al., 1990). En el caso de esta enfermedad, sería muy interesante investigar métodos de combate que eliminen las esporas del suelo, que finalmente son la principal fuente de inóculo. Lo anterior implicaría, por ejemplo, incursionar en el control biológico y en el desarrollo de fungicidas altamente específicos y no contaminantes ni tóxicos al resto de los organismos del ecosistema, incluyendo al hombre. Para esto, así como para la formación de variedades resistentes, y al igual que con otros problemas fitopatológicos, es muy conveniente la integración de grupos interdisciplinarios de investigación en fitopatología y en biotecnología, con el fin de acelerar la solución de los problemas de este tipo.

Estos dos últimos casos, el de la contaminación del grano de maíz con las aflatoxinas y el del carbón parcial del trigo, sirven para ilustrar algunos de los problemas y de las investigaciones que se pueden realizar, con el fin de aminorar o solucionar los problemas que los patógenos han creado en torno a las actividades agrícolas y comerciales del hombre, en la producción de alimentos de alta calidad industrial y sanitaria.

\section{TENDENCIAS Y PERSPECTIVAS DE LA INVESTIGACIÓN EN FITOPATOLOGÍA}

A continuación se describirán algunas de las tendencias de la investigación en la fitopatología que se han desarrollado en los últimos veinte años, como es la físiología de la interacción planta/patógeno, que es un elemento importante para la interacción de la fitopatología con la biotecnología, y cuyo desarrollo en México, puede impactar favorablemente el desarrollo de la fitopatología moderna que necesita la agricultura nacional.

El estudio de la fisiología de la interacción patógeno/ planta, se inició hace poco más de 20 años. Hay varias líneas de investigación dentro de esta área, como es el caso de las toxinas producidas por patógenos como las bacterias y los hongos. Sin embargo, el papel de pocas de estas substancias ha sido realmente relacionado con el desarrollo de la enfermedad. Muchas de estas substancias pertenecen a especies de Alternaria o Helminthosporium, que son parásitos facultativos. ¿Cuál es la razón de esto? Para responder a esa pregunta, se requiere más investigación.

Parece ser que la producción y el efecto de las toxinas está relacionado con la forma de vida de los patógenos, ya sean parásitos facultativos o parásitos obligados. En apariencia, el papel de las toxinas es muy claro: los patógenos las producen al momento de la infección, o aun antes de que este evento ocurra; las toxinas dañan a las células de la planta, facilitándose así el desarrollo del hongo, y finalmente se expresan los síntomas de la enfermedad. Desafortunadamente la situación no es tan simple. Al ser invadidas las plantas susceptibles por los parásitos obligados, que requieren células vivas para desarrollarse, supuestamente las toxinas sólo se activarían en muy bajas concentraciones, si es que esa situación se diese y las toxinas fuesen responsables de la enfermedad. La pregunta que aquí surge, es: ¿ ¿son estas toxinas las responsables de la resistencia por matar a las células? Si ésto es así, la susceptibilidad dependería de que las células de la planta no muriesen por la acción de las toxinas. Esta posibilidad no ha sido investigada en la forma 
que amerita, tal vez debido a las dificultades de trabajar con una toxina producida in vivo, y también debido al crecimiento tan lento de los parásitos obligados, aun cuando éstos puedan ser cultivados in vitro. Estos problemas no se tienen con los parásitos facultativos, ya que éstos producen in vitro las toxinas que reproducen los síntomas causados por los patógenos en las plantas. Esta situación ha ocasionado mucha confusión en relación con la actividad de las toxinas, ya que definir la toxicidad de una sustancia producida in vitro, es el paso inicial en el estudio del papel de estas sustancias en el desarrollo de una determinada enfermedad y no el paso final, como muy frecuentemente se encuentra descrito en la literatura. De tal manera, que en el laboratorio se han identificado químicamente un buen número de toxinas, de las que no se ha establecido con certeza el papel que desempeñan en las enfermedades, situación que hay que investigar. Este tipo de conocimiento sobre la forma de acción de los patógenos facultativos y los patógenos o parásitos obligados, se está investigando en el área de la biología molecular o la biotecnología, como se verá más adelante.

\section{La interacción de la fitopatología y la biotecnología}

La domesticación de las plantas, el mantenimiento de la variación genética de las plantas silvestres, las manipulaciones del hombre para la obtención de mejores plantas y productos como el pan y la cerveza, elaborados con las levaduras; la elaboración de otras bebidas y productos fermentados o « curados» con microorganismos, son ejemplos de la biotecnología emanada de la creatividad del hombre. Esta biotecnología popular se ha convertido, a través del tiempo, en lo que ahora se conoce como la biotecnología moderna. Su transformación se ha debido al avance de diversas disciplinas científicas, en particular de la biología molecular, la cual tuvo un gran impulso después del descubrimiento de la estructura molecular del ADN.

Podemos definir a la biotecnología moderna como la aplicación de los conocimientos de la biología molecular y de las técnicas que se han derivado de su ejercicio, como lo son el cultivo de tejidos y la ingeniería genética. Sus logros hacen ver el futuro de la producción de alimentos con gran optimismo. Lo que aun no está muy claro es la situación del hombre, principalmente el del campo, en cuanto a su capacidad para tener acceso a los bienes generados por los avances tecnológicos actuales y del futuro.

Una de las principales tendencias de la biotecnología es la de acelerar la obtención de cultivares con características altamente deseables, que permitan producir alimentos bajo condiciones que actualmente son limitantes (sequía, salinidad, bajas y altas temperaturas, resistencia a plagas y a enfermedades, etc.) dando lugar a una agricultura limpia y de alta productividad, que vaya acorde a la preservación del medio ambiente.

Los avances actuales de la biología molecular han sido estimulantes para la investigación en la fitopatología y en general para toda actividad productiva del sector agropecuario. Este nuevo enfoque y esfuerzo deberá dirigirse a ciertas áreas importantes, como las siguientes.

\section{Identificación de genes}

La gran diversidad biológica de nuestro país permitirá localizar, identificar y utilizar genes de importancia para la agricultura, entre ellos los de resistencia a patógenos. La diversidad es probablemente la principal barrera para el desarrollo de los patógenos de las plantas silvestres. La mezcla de diversos genotipos y por ende de diversas respuestas de las plantas silvestres a los patógenos, presenta un medio muy difícil para el desarrollo de las enfermedades. Los fitomejoradores por su parte, han seleccionado genotipos muy homogéneos, ideales para ser invadidos en forma intensiva por los nuevos genotipos del patógeno ya que éste también está tratando de sobrevivir.

Ya se ha tenido éxito en la identificación de genes de resistencia a diferentes enfermedades, como las royas de la linaza y del maíz causadas por Melampsora lini y por Puccinia sorghi, respectivamente (Saxena y Hooker, 1968; Wicks y Hammond, 1978; Hoes y Kenaschuk, 1986). Las técnicas modernas de la biotecnología abren una amplia perspectiva para la identificación de un mayor número de genes de resistencia a enfermedades de una manera más rápida y efectiva, así como para su incorporación a las plantas deseadas.

\section{Regulación de genes}

Se debe lograr un buen entendimiento de la regulación y la expresión de los genes importantes, así como de los métodos para utilizarlos en la ingeniería genética. Un problema surgido en la modificación de las plantas, ha sido la obtención de la expresión correctamente regulada de los genes en los tejidos del organismo seleccionado. Por ello tiene que investigar la estructura y función de los productos de esos genes en el metabolismo de las plantas, y en el desarrollo de las características agronómicas deseables, como lo es la resistencia a los patógenos. ¿Cuáles son los productos de los genes de resistencia a las enfermedades y como confieren esta resistencia? Se expresan estos genes en todos los tejidos de las plantas? Están estos productos ya preformados en las plantas? Es la respuesta de los genes inducida por el ataque de los patógenos? Estas son algunas de las preguntas que se han hecho los investigadores y a las cuales se les están buscando respuestas.

Lo señalado anteriormente sobre la fisiología del parasitismo, en cuanto al papel de las toxinas producidas por los patógenos y a su responsabilidad en el desarrollo de las enfermedades, la situación de los parásitos facultativos contra los parásitos obligados puede abordarse desde otro punto de vista. En el caso de los parásitos obligados, la asociación es muy específica; no todas las razas de un determinado patógeno son capaces de atacar a todos los 
individuos de una misma especie de planta. En otras palabras, las razas de un patógeno difieren en su habilidad para atacar a los diferentes cultivares de una especie, como lo es el caso de la roya del tallo del trigo. En los casos en que los cultivares de una especie de planta difieren en su susceptibilidad o resistencia a una raza de un patógeno, los estudios genéticos revelan comúnmente que la resistencia es conferida por un sólo gen, el cual usualmente es dominante sobre el alelo de la susceptibilidad.

Por su parte, cuando las razas de un patógeno difieren en su reacción de patogenicidad o no patogenicidad sobre una determinada planta, los estudios genéticos en los cuales los genes de no patogenicidad son dominantes sobre los de patogenicidad, han mostrado que un sólo gen puede ser el responsable de la diferencia. Cuando la información genética en este tipo de enfermedades causadas por parásitos altamente específicos es suficiente, tanto en lo que se refiere al patógeno como a la planta, es común encontrar la relación de gen por gen, en cuanto a la resistencia de la planta y a la patogenicidad del parásito (Flor, 1956). Generalmente la resistencia de las plantas a estas razas de parásitos obligados se manifiesta a través de una reacción de hipersensibilidad, por la cual las células de la planta atacada mueren limitando el futuro desarrollo del parásito, que sólo puede vivir en tejido vivo. No obstante que ésto se conoce desde hace décadas, y considerando que estas son enfermedades de gran importancia económica, poco se ha investigado sobre los mecanismos básicos de los fenómenos a nivel molecular que ocurren entre la planta «resistente» y el patógeno que no prospera y lo mismo en el sentido opuesto, o sea la planta susceptible y el patógeno que sí prospera, causando la enfermedad. La investigación en esta área es de gran importancia para la acción que la ingeniería genética puede tener en la solución de estos problemas fitopatológicos.

Se puede decir que los genes de resistencia de una planta para una determinada enfermedad son definidos más por sus efectos fenotípicos y por sus propiedades genéticas, que por sus productos, por lo que la identificación de los productos de los genes es una área prioritaria de investigación.

La identificación de los productos de los genes de resistencia, hará posible aplicar en forma más directa las técnicas para aislar y clonar genes que tengan productos identificables, proteínas o ARNm, que puedan ser usados en los programas de selección de genes resistentes. Esta situación sugiere dos estrategias, la primera de ellas se refiere a la clonación de genes sin conocer sus productos; la segunda es la de concentrar esfuerzos para determinar los productos de los genes y así poder utilizar las técnicas de clonación de genes que actualmente se conocen (Ellis, 1988).

En la primer estrategia, cuando no hay información del producto de un gen, ARNm o proteína, el reto para el investigador consiste en aislar el gen adecuado del genoma total de la planta en estudio, el cual generalmente es grande. Una posibilidad de lograrlo sería utilizando la clonación por medio de la técnica conocida como «shot-gun». Esta técnica para clonar genes ha sido usada con éxito en el caso de bacterias, como fue el caso de la clonación de genes de no patogenicidad de la bacteria patógena, Pseudomonas syringae (Staskawicz et al.,1984). El genoma de las bacterias es relativamente pequeño comparado con el de las plantas, por lo que un serio problema de eate procedimiento es el gran número de plantas transformadas que se requieren para tener una alta probabilidad de que se detecten plantas con el gen de resistencia. Jones et al. (1985) calcularon que para linaza o lino, si estaban presentes cuatro genes de resistencia en el genoma, que es pequeño, se requerían por lo menos un número de plantas transformadas no menor a 104 . Al calcular este número, ellos asumían que todos los segmentos de ADN tenían la misma probabilidad de ser clonados y transferidos a la población de plantas transformadas, suposición que puede no ser correcta.

La segunda estrategia, la de identificar los productos de los genes de resistencia, se enfrenta al problema de definir si la expresión de estos genes de resistencia es constitutiva o si es inducida por el ataque del patógeno. Si el gene de resistencia es inducido por el patógeno, la población total de ARNm o proteínas en los tejidos de las plantas puede ser comparada. Sin embargo, existe el problema de que un patógeno puede inducir la expresión de varios genes, por ejemplo los asociados con la producción de fitoalexinas y con la síntesis de proteínas relacionadas a la patogénesis, como las quitonasas y las glucanasas (Collinge y Slusarenko, 1987; Hedin, 1990; Linthorst, 1991). Estos genes no son de resistencia, sino que son genes de respuesta a la enfermedad, los que se expresan como una reacción al ataque del patógeno; pueden también ser disparados por otros agentes, no bióticos, que alteran la fisiología normal de la planta (Ellis et al.,1988).

El estudio de las proteínas relacionadas a la patogénesis, como las antes mencionadas, así como las tioninas, proteínas pequeñas ricas en azufre, que en cebada se han encontrado relacionadas con la resistencia contra el mildiú de la cebada (Erysiphe graminis f.sp.hordei), representa una área importante en la investigación fitopatológica, que ya ha permitido dilucidar algunas de las respuestas que las plantas tienen bajo la presión de los patógenos (Linthorst, 1991; Bohlmann, 1994).

Si el gen de resistencia es constitutivo en su acción, la identificación de los productos del gen se lleva a cabo por la comparación de los productos de una planta resistente con los de una planta que tiene la supresión del gen de resistencia. Para lograr esto es necesario contar con marcadores genéticos, que permitan confirmar que el gen de resistencia ha sido suprimido. Todo esto representa un amplio e importante reto de investigación, para la que se requiere de fitopatólogos y de biotecnólogos con una sólida formación científica y un claro entendimiento de las técnicas de la biología molecular requeridas para resolver estos problemas.

Cuanto más se conozca de la estructura y de la función de los genes de resistencia, se hará más factible el logro de resistencias estables a las enfermedades a través de la ingeniería genética, así como la creación de genes de 
resistencia. Las investigaciones de la última década que han hecho posible el desarrollo de mecanismos muy novedosos para la resistencia de las plantas a los virus, son ejemplos de lo importante que es el conocimiento básico de la biología molecular en la solución de problemas fitopatológicos (Gerlach et al.,1987; Harrison et al., 1987; Hull y Davies, 1992).

Desarrollo de técnicas para el cultivo de células, manejo de embriones y regeneración de plantas.

Desde hace muchos años estas técnicas han demostrado su valor en la obtención de plantas libres de patógenos, como el caso de las enfermedades virales. Sin embargo, es necesario el continuar buscando técnicas más adecuadas a las necesidades del quehacer científico y tecnológico.

Desarrollo de métodos rápidos y precisos para la identificación de enfermedades

La identificación de enfermedades a nivel molecular permitirá detectar las enfermedades en una etapa muy temprana del desarrollo de la enfermedad, lo que facilitará la toma de medidas para su control ( Miller y Martin, 1988).

\section{Realización de investigaciones sobre la bioquímica de} los fitopatógenos

Entre los fitopatógenos, los hongos filamentosos son los patógenos más importantes de las plantas y muy poco se sabe de la bioquímica de éstos en comparación con, por ejemplo, lo que se sabe del hongo unicelular Saccharomyces cerevisiae. El conocimiento básico de la bioquímica de los hongos permitirá definir mejores estrategias para el control de los patógenos, abriendo el camino hacia los genes que deberán ser clonados, así como definiendo su papel en el metabolismo de las plantas transgénicas y en el fenómeno de la patogenicidad.

\section{Estudios sobre la genética de los hongos fitopatógenos}

El estado sexual de patógenos importantes como Mycosphaerella graminicola no está bien conocido y el de Tapesia vallundae no se puede manejar bien experimentalmente (Nicholson et al., 1991). Además de las ventajas que se tendría para la comprensión de los fenómenos de patogenicidad y no patogenicidad, estos estudios pueden ser de gran utilidad para entender las bases genéticas de la resistencia a los fungicidas, y así poder formular estrategias biológicas que resuelvan este problema en el uso de los fungicidas.

Investigación y comprensión del comportamiento de los organismos transgénicos en los ecosistemas naturales y agrícolas.

Este es un tema importante para la salvaguarda de los recursos genéticos del mundo, cuyos avances son importan- tes para definir las estrategias de manejo de los organismos transgénicos.

Por otra parte, es importante estudiar con gran detalle las dificultades y la naturaleza de las estrategias que los patógenos tienen para establecerse y desarrollarse en las plantas y causar las enfermedades, de tal manera que esos conocimientos nos permitan un mejor manejo de las mismas (Paxton y Groth, 1994). Lo anterior significa conocer a nivel molecular la biología del patógeno, así como la interacción del patógeno con la planta. Como ejemplo de esto último, se puede citar el caso de Agrobacterium tumefaciens, causante de la enfermedad «agalla de la corona» en diversas plantas; esta bacteria «ha aprendido» a crear su muy exclusivo nicho dentro de las plantas, al insertar su ADN en los cromosomas de las plantas parasitadas, las que así producen nutrientes que sólo pueden ser utilizados por esta bacteria (Kado, 1991). Este conocimiento sobre la manera que $A$. tumefaciens maneja su $\mathrm{ADN}$, ha permitido además grandes avances en la genética molecular.

Las perspectivas de investigación en el área de la agricultura y en particular de la fitopatología son muy grandes. Para un país como el nuestro, es importante seleccionar los problemas que limitan o han de limitar la actividad agrícola, entre ellos las enfermedades de las plantas. Para esto es importante integrar grupos interdisciplinarios que se aboquen a su solución. Para un desarrollo competitivo del sector agrícola, es necesario reforzar la investigación básica con programas sólidos en bioquímica, en fisiología, en genética y biología molecular, dentro de las disciplinas de la agronomía, como son el fitomejoramiento, la entomología, la fitopatología y la relación suelo- planta- agua, entre otras no menos importantes.

Hay que resaltar que en el mundo hay gran demanda de una tecnología agrícola limpia y competitiva - acorde a las necesidades de una sociedad cada día más consciente de la conveniencia de preservar la calidad del ambiente- con el fin de resolver los problemas más apremiantes de la producción de alimentos. En este sentido el desarrollo de la Fitopatología moderna, apoyado en la biología molecular, es un asunto prioritario.

Considerando los avances recientes en la biotecnòlogía, los planes de estudio de las licenciaturas y posgrados en fitopatología tienen que adecuarse a las exigencias del desarrollo general de la ciencia, y en este caso muy en particular del de la biología molecular. El fitopatólogo moderno tiene que estar formado de una manera muy sólida, acorde a los avances y tendencias de la ciencia. Pero no está por demás recordar siempre las palabras del Dr. Elvin C. Stakman: «No hay que olvidar a qué profundidad se siembra el trigo».

\section{LITERATURA CITADA}

Ahl Goy P, Metraux JP, Speich J, Staub T. 1990. Derivatives of isonicotinic acid induce resistance to viruses, bacteria and fungi in tobacco. (Abstr.) Int. Symp. Mol. Genet. Plant-Microbe Interact., 5th Interlaken, Switzerland, p.224. 
Bohlmann H. 1994. The role of thionins in plant protection. Crit. Rev.Plant Sci. 13: 1-16.

Carson R. 1962. Silent spring. The Riverside Press Cambridge.

Collinge DB, Slusarenko AJ. 1987. Plant gene expression in response to pathogens. Plant Mol. Biol: 9: 389-410.

Dekker J. 1986. Preventing and managing fungicide resistance.En: Pesticide resistance: strategies and tactics for management. National Research Council (U.S.), Commitee on Strategies for the management of pesticide resistant pest populations. National Academy Press, Washington, D.C.

Duran R. 1972. Further aspects of teliospore germination. North American smut fungi II. Can.J. Bot. 50: 2569- 2573.

Ellis JG, Lawrence GJ, Peacock WJ, Pryor AJ. 1988. Approaches to cloning plant genes conferring resistance to fungal pathogens. Annu. Rev. Phytopathol. 26: 245-263.

Flor HH. 1956. The complementary genic systems in flax rust. $A d v$. Genet. 8: 29-54.

Gerlach WL, Llewellyn D, Haseloff J. 1987. Construction of a plant disease resistance gene from the satellite RNA of tobacco ringspot virus. Nature 328: 802-805.

Gill KS, Nanda GS, Singh G, Chand K, Aujla SS, Sharma I. 1990. Study of gene effects for karnal bunt (Neovosia indica Mitra) resistance in bread wheat (Triticum aestivum L.). Indian J. Genet. 50: 205-209.

Gilpatrick JD. 1983. Management of resistant in plant pathogens. En: Georghiou GP, Saito T, edrs.Pest resistant to pesticides Plenum Press, New York, 735-767.

Harrison BD, Mayo MA, Baulcombe DC. 1987. Virus resistance in transgenic plants that express cucumber mosaic virus satellite RNA. Nature 328: 799-802.

Hedin PA. 1990. Bioregulator-induced changes in allelochemicals and their effects on plant resistance to pests. Crit. Rev. Plant Sci. 19: 371-379.

Hoes JA, Kenaschuk EO. 1986. Gene K' of Raja Flax: A new factor for resistance to rust. Phytopathology 76: 1043-1045.

Hull R, Davies JW. 1992. Aproaches to nonconventional control of plant virus diseases. Crit. Rev. Plant Sci. 11: 17-33.

Jones DA, Zhan XC, Kerr A. 1985. To clone a gene from flax (Linumusita tissimum) for resistance to flax rust (Melamsora lini). En: Susex I, Ellingboe A, Crouch M, Malmberg R, edrs.Current communications in molecular biology: plant cell interactions. New York: Cold Spring Harbor Lab.

Kado CI. 1991. Molecular mechanisms of crown galltumorigenesis. Crit. Rev. Plant Sci. 10: 1-32.
Large EC. 1962. The advance of the fungi. Dover Publications, Inc. New York.

Linthorst HJM. 1991. Pathogenesis-related proteins of plants. Crit. Rev. Plant Sci. 10: 123-150.

Miller S A, Martin RR. 1988. Molecular diagnosis of plant disease. Annu. Rev. Phytopathol. $26: 409-432$.

Mitra M. 1937. Studies on the stinking smut of wheat in India. Ind. J. Agr. Sci. 7: 459-478.

Moreno ME. 1985. Development of resistant varieties: one option for reducing mycotoxin production. Second International Conference on Mycotoxins. FAO. Sept. 28. Bankog, Thailand.

Moreno ME, Gil GM. 1991. La biología de Aspergillus flavus y la producción de aflatoxinas. Programa Universitario de Alimentos, UNAM, México.

Nicholson P, Rezanoor HN, Hollins TW.1991. Occurrence of Tapesia vallundae apothecia on field and laboratory-inoculated material and evidence for recombination between isolates. Plant Pathol. 40: 626-634.

Payne GA. 1992. Aflatoxin in maize. Crit. Rev. Plant Sci.10: 423-440.

Paxton JD, Groth J. 1994. Constrains on pathogens attacking plants. Crit. Rev. Plant Sci. 13: 77-95.

Pettersson O. 1993. Swedish pesticide policy in a changing environment. En: Pimentel D, Lehman $\mathrm{H}$, edrs. The pesticide question: environment, economics and ethics Chapman and Hall, New York.

Prevost B. 1807. Mémoire sur la cause immediate de la carie ou charbon des blès, et de plusierus autres maladies des plants, et sur les préservatifs de la carie. Paris. Phytopatol. Classics 6: 1939.

Saxena KMS, Hooker AL. 1968. On the structure of a gene for disease resistance in maize. Proc. Nat. Acad. Sci. USA 61: 1300-1305.

Staskawicz BJ, Dahlbeck D, Keen NT. 1984. Cloned avirulence gene of Pseudomonas syringae pv.glycinea determines race-specific incompatibility on Glycine max (L) Merr.Proc. Nat. Acad.Sci., USA 81: 6024-6028.

Staub T, Sozzi D. 1984. Fungicide resistance: a continuing challenge. Plant Dis. 68: 1026-1031.

Tillet M. 1755. Disertation sur la cause qui corrompt et noircit les grains de bled dans les épis; et sur les moyens deprévenir ces accidens. Bordeux. Phytopathol. Classics 5: 1937.

Tulasne LR, Tulasne C. 1847. Mémoire sur les Ustilagnées comparées aux Urédinées. Ann. Sci. Nat., Ser. 7: 12-127.

Wicks ZW, Hammond JJ. 1978. Screening of flax species for new sources of genes resistant to Melampsora lini (Ehreneb.) Lev. Crop Sci. 18: 7-10. 